\title{
Silencing of BRF2 inhibits the growth and metastasis of lung cancer cells
}

\author{
YUAN BIAN $^{1}$, QIU LI ${ }^{1}$, QIAOLIAN LI ${ }^{1}$ and RUIGEN PAN ${ }^{2}$ \\ Departments of ${ }^{1}$ Respiratory Medicine and ${ }^{2}$ Radiology, Zhuji Affiliated Hospital \\ of Shaoxing University, Zhuji, Zhejiang 311800, P.R. China
}

Received January 6, 2020; Accepted May 15, 2020

DOI: $10.3892 / \mathrm{mmr} .2020 .11285$

\begin{abstract}
Transcription factor II B (TFIIB)-related factor 2 (BRF2) is involved in the development of cancer, but its role in lung cancer is underreported. The present study aimed to explore the role of BRF2 in the regulation of lung cancer cells. Immunofluorescence staining and immunohistochemistry were performed to detect BRF2 protein expression in human lung cancer cells and tissues. Following cell transfection with small interfering RNA for silencing BRF2, the cell proliferation was examined by Cell Counting Kit-8 and MTT assays. Cell apoptosis, migration and invasion were determined by flow cytometry, wound-healing and Transwell assay. The expression levels of Akt, phosphorylated (p)-Akt, Bax, E-cadherin, Bcl-2, N-cadherin, Snail and epidermal growth factor receptor (EGFR) in human lung cancer A549 cells were detected by western blotting. The results demonstrated that BRF2 expression was increased in human lung cancer cells and tissues, and that silencing of BRF2 promoted cell apoptosis but inhibited cell proliferation and migration. The protein expression levels of Akt, E-cadherin, p-Akt, Bcl-2, N-cadherin, Snail and EGFR in A549 cells were inhibited by silencing of BRF2, while expression levels of Bax and E-cadherin were increased by silencing BRF2. In conclusion, BRF2 demonstrates high expression in lung cancer and silencing of BRF2 inhibits the growth and metastasis of lung cancer cells. The current findings provide a novel approach for the treatment of lung cancer.
\end{abstract}

\section{Introduction}

Lung cancer is an aggressive malignant tumor with poor therapeutic outcomes (1). Patients with non-small cell lung cancer (NSCLC) account for the majority of lung cancer cases and the incidence of NSCLC is increasing annually (2-4).

Correspondence to: Dr Yuan Bian, Department of Respiratory Medicine, Zhuji Affiliated Hospital of Shaoxing University, 9 Jianmin Road, Taozhu Street, Zhuji, Zhejiang 311800, P.R. China

E-mail: bianyuan_ybi@163.com

Key words: invasion, lung cancer, metastasis, transcription factor II B-related factor 2, BRF2, proliferation
Thus, developing effective and novel biomarkers and targets for lung cancer diagnosis and therapy is urgent.

Transcription factor II B (TFIIB)-related factor 2 (BRF2) is a gene located on chromosome 8p12 (5). As a subunit, BRF2 protein, which is located on TFIIB and participates in small RNA production, is catalyzed under RNA polymerase III (pol III) (6-9). During cell cycle, the transcription of RNA pol III is regulated to ensure normal cellular growth $(10,11)$. Previous studies reported that RNA pol III activity plays a key role in the deregulation of a variety of cancers, regardless of tissue types $(12,13)$. Deregulation of TFIIIB-mediated transcription is an important factor in tumor development (14). In addition, TBP expression is found increased in a large number of cancers including in human kidney, colon, melanoma, and gastric cancers $(15,16)$.

BRF2 has a pivotal role in proliferation, metastasis, angiogenesis, and tumorigenesis by acting as an oncogene (2). In addition, overexpression of BRF2 is associated with a higher risk of cancer recurrence $(5,17)$. Lockwood et al (18) demonstrated that genetic activation of BRF2 is a special mechanism of squamous cell carcinoma tumorigenesis, and this finding is the first clinical evidence to suggest that BRF2 is a novel oncogene in lung cancer. Previous studies suggest that BRF2 expression is increased in breast cancers, suggesting that it is potentially a candidate oncogene $(19,20)$. However, the mechanism of action of BRF2 still remains to be elucidated, especially the relationship between BRF2 and lung cancer.

By using immunofluorescence staining and immunohistochemistry methods, the present study detected BRF2 protein expression levels in lung cancer tissues, and analyzed the function of the BRF2 gene in the metastasis of lung cancer cells.

\section{Materials and methods}

Clinical samples. The clinical samples of lung cancer tissue and paired normal adjacent tissues were collected from lung cancer patients at Zhuji Affiliated Hospital of Shaoxing University in 2019 for treatment. A total of 72 patients with lung cancer (age, 35-70 years) were enrolled between December 2018 and December 2019. The male to female ratio was 3:1. Patients were divided into three groups according to the age of onset as follows: Group 1, 35-50; group 2, 50-62; group 3, 62-70. Cancer and normal adjacent tissues of all patients were obtained and used to detect the gene expression level of BRF2 in the tissues. 
The patients had no history of chemotherapy and did not have other types of cancer, infectious diseases, or autoimmune diseases. All patients signed informed consent and agreed that their tissues would be used for clinical research. The study was approved by the Ethics Committee of Zhuji Affiliated Hospital of Shaoxing University (approval no. ZLK20181124). All clinical samples were obtained at the time of initial resection, and stored at $-80^{\circ} \mathrm{C}$.

Bioinformatics analysis. BRF2 mRNA expression levels in lung cancer and normal tissues were compared using a bioinformatics website (gepia.cancer-pku.cn).

Cell culture. Normal human lung epithelial cells (BEAS-2B; cat. no. CRL-9609) and human lung cancer cells (A549, cat. no. CCL-185; H292, cat. no. CRL-1848) were purchased from the American Type Culture Collection. The cells were cultured in Dulbecco's modified Eagle's medium (DMEM, Sigma-Aldrich; Merck KGaA) supplemented with $10 \%$ fetal bovine serum (FBS, Thermo Fisher Scientific, Inc.), $100 \mathrm{U} / \mathrm{ml}$ penicillin and $100 \mu \mathrm{g} / \mathrm{ml}$ streptomycin at $37^{\circ} \mathrm{C}$ in $5 \% \mathrm{CO}_{2}$.

Immunofluorescence staining. The cells $\left(2 \times 10^{4} / \mathrm{ml}\right)$ were grown on coverslips and after the liquid had been aspirated, the cells were covered 2-3 mm under $4 \%$ formaldehyde diluted in warm phosphate-buffered saline (PBS) to be fixed for $15 \mathrm{~min}$ at room temperature. Following removal of the fixative, the cells were rinsed in PBS with for $5 \mathrm{~min}$. Then the cells were blocked with immunostaining blocking buffer (cat. no. P0102; Beyotime Institute of Biotechnology) at $37^{\circ} \mathrm{C}$ for $60 \mathrm{~min}$, after aspirating the solution, primary antibody anti-BRF2 antibody (mouse, cat. no. ab194442, 1:500, Abcam) was added to the cells. Next, the cells were incubated overnight at $4^{\circ} \mathrm{C}$. The cells were rinsed 3 times in PBS for $5 \mathrm{~min}$ at room temperature in the dark, and then incubated with fluorochrome-conjugated secondary antibody [horseradish peroxidase (HRP)-conjugated goat anti-mouse IgG H\&L (1:100; cat. no. ab6789; Abcam)] at $37^{\circ} \mathrm{C}$ for $1 \mathrm{~h}$. DAPI (cat. no. D1306, Thermo Fisher Scientific, Inc.) was added to the cells and incubated together for $5 \mathrm{~min}$ in the dark. Following aspiration of the liquid, the cells were observed under a fluorescence microscope (magnification, x200; cat. no. BX43; Olympus Corporation).

Immunohistochemistry. Following fixation in $4 \%$ formaldehyde at $25^{\circ} \mathrm{C}$ for $24 \mathrm{~h}$, the tissues were dehydrated and made transparent by gradient alcohol, then paraffin-embedded, and sectioned (section thickness, $5 \mu \mathrm{m}$ ). The sections were soaked in citrate buffer solution ( $\mathrm{pH}$ 6.0) and heated in a $850 \mathrm{~W}$ power microwave oven for $10 \mathrm{~min}$ to conduct antigen repair. The endogenous peroxidase enzyme activity was minimized by rinsing the sections in $3 \% \mathrm{H}_{2} \mathrm{O}_{2}$ in methanol for $20 \mathrm{~min}$ at room temperature. Then, the tissues were incubated with primary rabbit anti-BRF2 polyclonal antibody (1:400, cat. no. ab194442, Abcam) at $4^{\circ} \mathrm{C}$ overnight. Next the sections were incubated with secondary antibody [HRP-conjugated goat anti-rabbit immunoglobulin (IgG) H\&L (1:2,000; cat. no. ab150113; Abcam) and streptavidin-peroxidase complex for $30 \mathrm{~min}$ at $37^{\circ} \mathrm{C}$. The sections were stained with hematoxylin, dried in an oven at $65^{\circ} \mathrm{C}$, rinsed in water, then mixed with alcohol and xylene and naturally dried. Finally, the sections were sealed and observed under an optical microscope (magnification, x100; BX53M, Olympus Corporation).

Cell transfection. BRF2 small interfering (si)RNA (cat. no. 11968 S, Cell Signaling Technology, Inc.) was transfected into the A549 cells using Lipofectamine ${ }^{\circledR} 2000$ Transfection reagent (Invitrogen; Thermo Fisher Scientific, Inc.). A549 cells were seeded into 6 -well plates at $1 \times 10^{5}$ cells per well and incubated at $37^{\circ} \mathrm{C}$ for $24 \mathrm{~h}$. Then $1.5 \mathrm{ml}$ medium without serum or antibiotics was added into each well of the plate, with the mixture of 100 pmol BRF2 siRNA and Lipofectamine ${ }^{\circledR} 2000$ to incubate for $4-6 \mathrm{~h}$ at $37^{\circ} \mathrm{C}$ with $5 \% \mathrm{CO}_{2}$. The siRNA sequences were as follows: BRF2 siRNA sense, 5'-GGUGGG AAAUAAUUCCUUATT-3'; si-negative control (siNC) sense, 5'-UUCUCCGAACGUGUCACGUTT-3'. After $72 \mathrm{~h}$ of transfection, the cells were collected for later analysis.

Reverse transcription-quantitative $(R T-q) P C R$. Total RNAs were extracted from tissues or cells $\left(2 \times 10^{4} / \mathrm{ml}\right)$ by TRIzol ${ }^{\circledR}$ reagent (Invitrogen; Thermo Fisher Scientific, Inc.) according to the manufacturer's protocols. Total RNAs were placed in a refrigerator at $4^{\circ} \mathrm{C}$, and quantified by a biological spectrometer (Nano Drop 2000C; Thermo Fisher Scientific, Inc.). The extracted RNAs were reverse-transcribed to cDNA using a Prime Script RT reagent kit (Takara Bio, Inc.) according to the manufacturer's instructions. The results were normalized to $\beta$-actin. Next, SYBR ${ }^{\circledR}$ Green PCR Master Mix (cat. no. 4312704, Applied Biosystems, Thermo Fisher Scientific, Inc.) and Bio-Rad CFX 96 Touch Real-Time PCR Detection system (cat. no. 1855196, Bio-Rad Laboratories, Inc.) were used for RT-qPCR, according to the manufacturer's instructions. The thermocycling conditions were as follows: $95^{\circ} \mathrm{C}$ for $5 \mathrm{~min}, 40$ cycles of $95^{\circ} \mathrm{C}$ for $15 \mathrm{sec}, 60^{\circ} \mathrm{C}$ for $30 \mathrm{sec}$ and $70^{\circ} \mathrm{C}$ for $10 \mathrm{sec}$. The primers for $\beta$-actin and BRF2 were: $\beta$-actin forward, 5 '-ATTGGCAATGAGCGGTTC-3' and reverse: 5'-GGATGCCACAGGACTCCA-3'; BRF2 forward, 5'-CACAGGGGAAAACGAACAAG-3' and reverse, 5'-TCGA CAAAGGTCTCTCACTCG-3'. The gene expression was calculated by the $2^{-\triangle \Delta C q}$ method (21). Each experiment was performed 3 times.

Western blotting. Following transfection for 48 h, A549 cells were collected for western blot analysis as previously described (22). Total proteins were extracted from the cells by RIPA lysis buffer (Thermo Fisher Scientific, Inc.), and protein concentration was determined by bicinchoninic protein assay kit (Sigma-Aldrich; Merck KGaA). The proteins (10 $\mu \mathrm{g})$ were separated by $10 \%$ SDS-PAGE (cat. no. P0012A, Beyotime Institute of Biotechnology) and transferred onto polyvinylidene fluoride membranes (cat. no. FFP28, Beyotime Institute of Biotechnology), which were blocked with $5 \%$ fat-free milk for $1 \mathrm{~h}$ at room temperature. The membranes were then incubated overnight at $4^{\circ} \mathrm{C}$ with the primary antibodies: anti-Akt antibody (rabbit, cat. no. ab8805, 1:500, Abcam), anti-p-Akt antibody (rabbit, cat. no. ab38449, 1:500, Abcam), anti-Bax antibody (rabbit, cat. no. ab32503, 1:1,000, Abcam), anti-Bcl-2 antibody (rabbit, cat. no. ab59348, 1:500, Abcam), anti- E-cadherin antibody (rabbit, cat. no. ab40772, 1:1,000, Abcam), anti-N-cadherin (rabbit, cat. no. ab18203, $1 \mu \mathrm{g} / \mathrm{ml}$, Abcam), anti-Snail antibody (rabbit, cat. no. ab229701, 1:1,000, Abcam), anti-EGFR antibody (rabbit, cat. no. ab52849, 1:1,000, 
Abcam) and anti- $\beta$-actin antibody (mouse, cat. no. ab8226, $1: 500$, Abcam). $\beta$-actin served as an internal reference. The membranes were then incubated with secondary HRP-conjugated antibodies [goat anti-rabbit IgG H\&L (HRP) (1:2,000; cat. no. ab150113; Abcam) and goat anti-mouse IgG H\&L (HRP) $\left(1: 2,000\right.$; cat. no. ab6789; Abcam] at $37^{\circ} \mathrm{C}$ for $1 \mathrm{~h}$ and washed 3 times with $0.9 \%$ TBST. The protein bands were developed by an enhanced chemiluminescence (ECL) kit (Millipore), and the grey values of the strips were calculated by ImageJ (version 5.0; National Institutes of Health) (23).

MTT assay. The A549 cells were incubated in 96-well plates at a density of $5 \times 10^{3}$ cells/well. Following transfection, the cells were cultured for $48 \mathrm{~h}$ with $5 \% \mathrm{CO}_{2}$ at $37^{\circ} \mathrm{C}$. Next, $20 \mu \mathrm{l}$ MTT (Promega Corp.) was added to each well. The formazan products were dissolved in $100 \mu 1$ dimethylsulfoxide (DMSO), and the absorbance was detected at $540 \mathrm{~nm}$ using a microplate reader (PR3100 TSC, Bio-Rad Laboratories, Inc.). The cells were subjected to a multifunctional enzyme-linked analyzer (Attune NxT; Thermo Fisher Scientific, Inc.) for $4 \mathrm{~h}$, and the absorbance value of each hole was measured at $490 \mathrm{~nm}$.

Cell Counting Kit- $8(C C K-8)$. The cells $\left(5 \times 10^{3}\right.$ cells/well) from the different treatment groups were seeded in a 96 -well plate, and cultured in an incubator with $5 \% \mathrm{CO}_{2}$ at $37^{\circ} \mathrm{C}$ for $48 \mathrm{~h}$. Next, $100 \mu \mathrm{l}$ CCK-8 and serum-free basic medium (DMEM; Thermo Fisher Scientific, Inc.) were mixed at a 1:10 ratio and added to a cell culture plate and cultured for $4 \mathrm{~h}$. Finally, the absorbance at $450 \mathrm{~nm}$ wavelength was determined using a microplate reader (RNE90002, Reagen Biology LLC).

Apoptosis assay. Following transfection, the A549 cells were washed with cold PBS twice. Annexin V/Dead Cell Apoptosis kit (cat. no. V13242, Thermo Fisher Scientific, Inc.) was used to identify apoptotic cells. Briefly, the cells were re-suspended in Annexin V binding buffer, added with Annexin V-FITC and propidium iodide (PI) buffer, and incubated at room temperature for $15 \mathrm{~min}$ in the dark. Cell apoptosis was analyzed using a flow cytometer (FACSCalibur ${ }^{\mathrm{TM}}$; version 2.0; BD Biosciences).

Wound-healing assay. Following transfection, the cells were subcultured in plates at a density of $1 \times 10^{5}$ cells/well and incubated in serum without FBS at $37^{\circ} \mathrm{C}$ for $24 \mathrm{~h}$. The wounds were created using a $200-\mu 1$ yellow sterile pipette tip on the monolayer, and detached cells were removed by washing the cells 3 times. The healing process was observed under a 600 Autobiochemical Analyzer (Olympus Corporation), and ImageJ software (Image Pro Plus; version 6.0; National Institutes of Health) was used to calculate the average distance between cells.

Transwell invation assay. Matrigel (BD Biosciences) diluted at a 1:8 ratio was used to cover the upper surface of the membrane of the bottom of Transwell chambers, and the chambers were incubated at $37^{\circ} \mathrm{C}$ for $30 \mathrm{~min}$ in order to polymerize the Matrigel into gel. The cells were resuspended in the upper chambers of the Transwell ( $8-\mu \mathrm{m}$ pore size, Corning Inc.), which contained serum-free DMEM medium, while the lower chambers were supplemented with DMEM containing $10 \%$ FBS. The Transwell chambers were all incubated for
$48 \mathrm{~h}$. Next, the cells remaining in the upper chamber were gently removed using a cotton swab, while the invaded cells were fixed in $4 \%$ paraformaldehyde for $15 \mathrm{~min}$ and stained by $0.1 \%$ crystal violet staining at $37^{\circ} \mathrm{C}$ for $20 \mathrm{~min}$. The cells were randomly counted under an inverted microscope (Eclipse Ti2, Nikon Corporation) and images were captured.

Statistical analysis. All data were statistically analyzed by SPSS version 18.0 (SPSS, Inc.). The data are presented as means \pm standard deviation, and all experiments were repeated 3 times. Two-group comparisons were conducted by the Student's t-test, and multi-group comparisons were conducted by one-way analysis of variance (ANOVA) followed by Dunnett's post hoc test. $\mathrm{P}<0.05$ was considered to indicate a statistically significant difference.

\section{Results}

BRF2 expression levels are increased in lung cancer tissues and cells. To investigate whether BRF2 is involved in tumor migration and invasion, its protein expression in normal human lung epithelial BEAS-2B cells and lung cancer cells A549 and H292 were detected by immunofluorescence staining. As shown in Fig. 1A, marker protein BRF2 was positively expressed in A549 and H292 cells, especially in the A549 cells, while in BEAS-2B cells, marker protein BRF2 demonstrated a low expression. Meanwhile, BRF2 expression was detected by western blotting, as shown in Fig. $1 \mathrm{~B}$ and $\mathrm{C}$; BRF2 expression was significantly increased in A549 and H292 cells compared to that noted in the BEAS-2B cells. In addition, according to Fig. 1D, BRF2 protein staining was detected in cancer tissues by immunohistochemistry; however, BRF2 was barely observed in normal lung tissues. As shown in Fig. 1E, the BRF2 mRNA expression levels in lung cancer tissues and normal tissues were compared using a bioinformatics website (gepia.cancer-pku.cn), and the result demonstrated that the BRF2 mRNA expression level in the tumor tissues was notably higher compared with normal tissues. The BRF2 mRNA expression in lung cancer A549 and H292 cells and normal lung epithelial BEAS-2B cells was detected by RT-qPCR. Relative BRF2 mRNA expression level was the highest in A549 cells (Fig. 1F, P<0.001) and its protein expression was also high in $\mathrm{H} 292$ cells, while the mRNA expression level of BRF2 in BEAS-2B cells was low. In addition, normal adjacent and cancer tissues were divided into groups 1-3. Relative BRF2 mRNA expression level in lung cancer cells was clearly higher than normal cells (Fig. 1G, P<0.001).

Knockdown of BRF2 inhibits the proliferation of A549 cells. To explore the role of BRF2 in lung cancer cells, A549 cells were transfected with siRNA for silencing BRF2. As shown in Fig. 2A, $48 \mathrm{~h}$ after BRF2 siRNA transfection, the result of RT-qPCR demonstrated that the relative mRNA expression level of BRF2 in A549 cells was significantly lower than that in the siNC group $(\mathrm{P}<0.001)$. The result of western blotting (Fig. 2B) demonstrated that the relative protein expression level of BRF2 was significantly inhibited ( $\mathrm{P}<0.001$ vs. siNC). In addition, the results of the CCK-8 and MTT assays demonstrated that after transfection for $48 \mathrm{~h}$ the relative cell viability of A549 cells in the siRNA group was significantly inhibited compared with the siNC group (Fig. $2 \mathrm{C}$ and $\mathrm{D},{ }^{* *} \mathrm{P}<0.01$ ). 


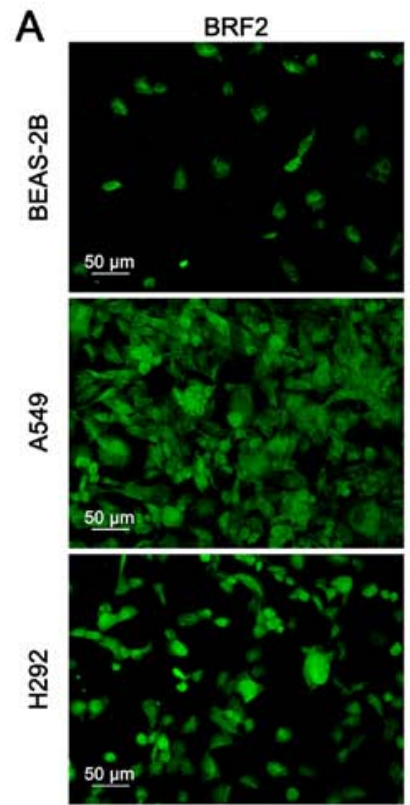

B

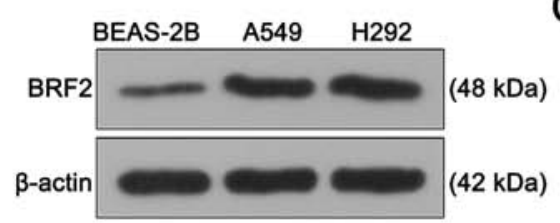

D

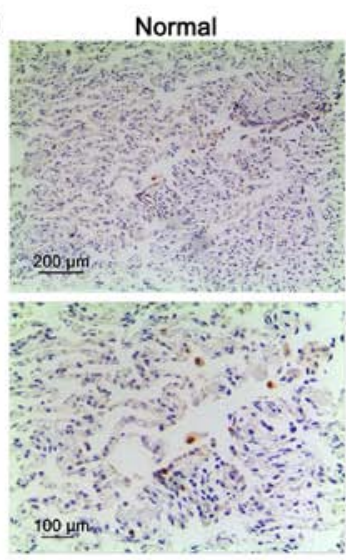

$\mathrm{F}$

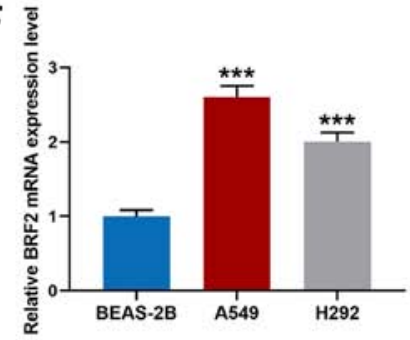

$\mathrm{G}$
Dapi
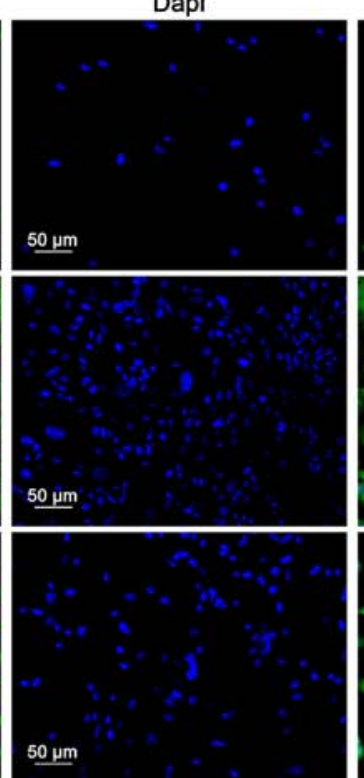

C

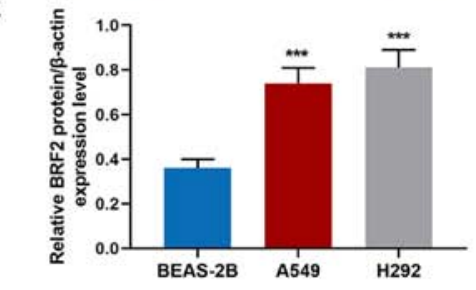

E

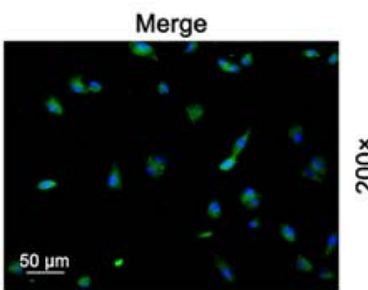

ㅇํํ
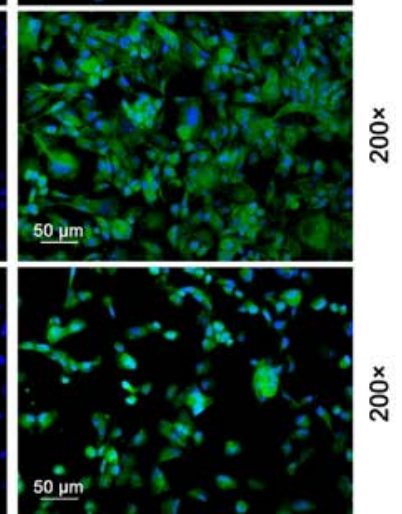

옹

ลั่

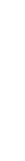
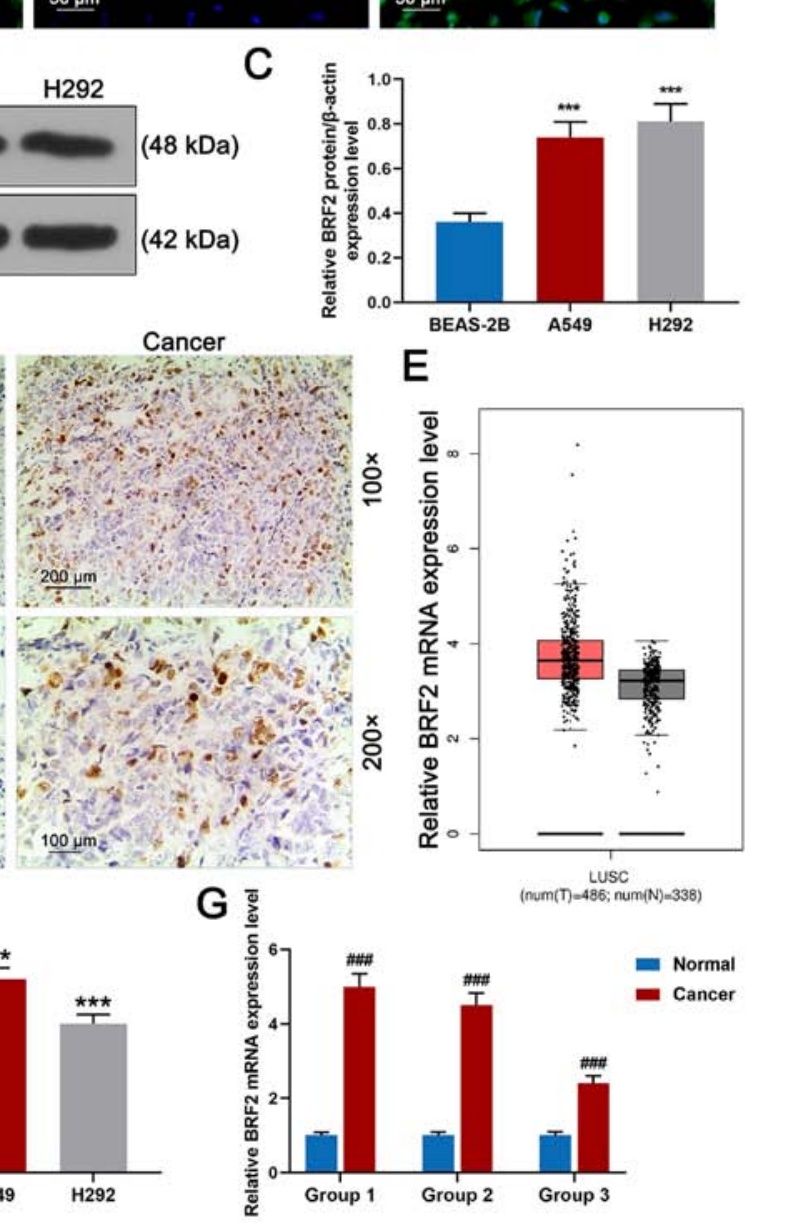

Figure 1. BRF2 protein expression in lung cancer tissue and cells. (A) BRF2 expression in normal human lung epithelial BEAS-2B cells and lung cancer A549 and H292 cells was detected by immunofluorescence staining. Magnification, x200; scale bar, $50 \mu \mathrm{m}$. (B and C) BRF2 expression was detected by western blotting. (D) BRF2 expression in a normal adjacent tissue group (normal, $\mathrm{n}=3$ ) and cancer group ( $=3$ ) was detected by immunohistochemistry. Magnification, $\mathrm{x} 100$; scale bar, $200 \mu \mathrm{m}$. (E) The BRF2 mRNA expression level in lung cancer tissues and normal tissues was compared by bioinformatics website (gepia.cancer-pku. $\mathrm{cn}$ ). (F) RT-qPCR revealed that the A549 cell group had the highest relative BRF2 mRNA expression level, while the expression level in the BEAS-2B cell group was the lowest. (G) Normal adjacent tissues and cancer tissues were divided into groups 1 (onset age, 35-50 years), 2 (onset age, $50-62$ years) and 3 (onset age, 62-72 years). RT-qPCR demonstrated that BRF2 protein had a high expression in the cancer groups. The experiments were repeated at least 3 times. ${ }^{* * *} \mathrm{P}<0.001$ vs. BEAS-2B; \#\#P<0.001 vs. normal group. BRF2, transcription factor II B-related factor 2; RT-qPCR, reverse transcription-quantitative PCR.

Knockdown of BRF2 promotes apoptosis and inhibits cell migration and invasion of A549 cells. Following transfection, the effects of siRNA on cell apoptosis and migration were assessed. As shown in Fig. 3A, flow cytometry demonstrated that the rate of apoptosis of the siRNA group was significantly higher compared with that noted in the siNC group (Fig. 3A, 

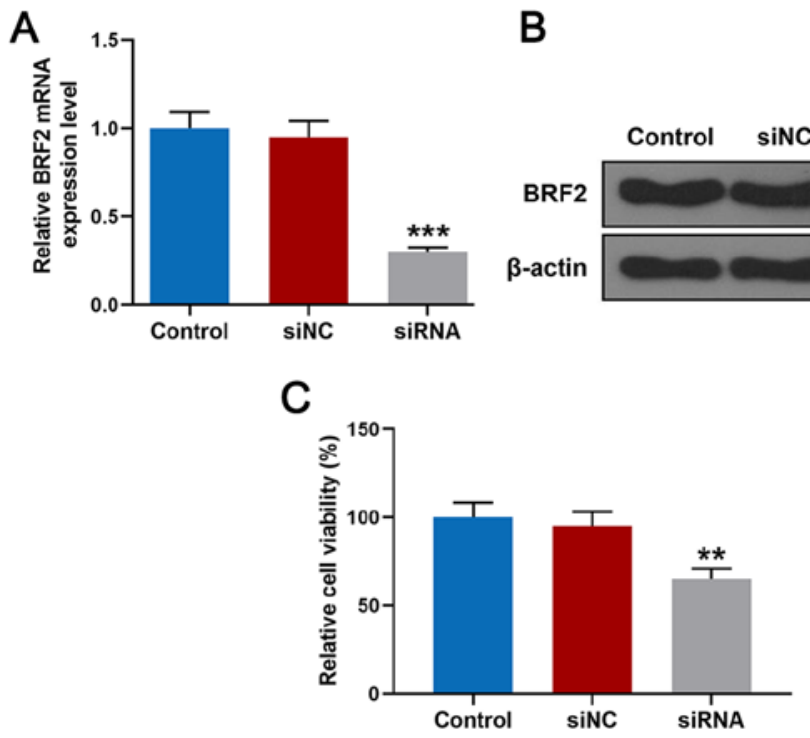

B

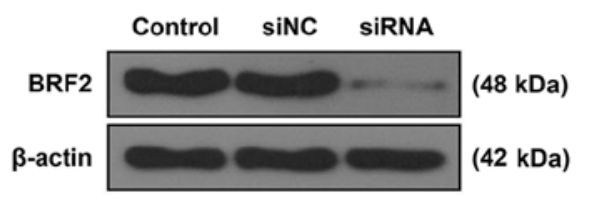

D

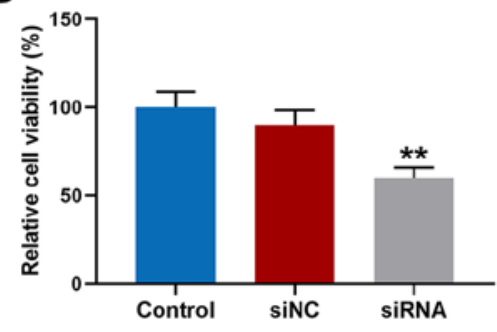

Figure 2. Effects of BRF2 siRNA on the proliferation of A549 cells. (A) A549 cells were transfected with siRNA (siRNA group) and siNC (siNC group), the control group was set up and the transfection efficiency was detected by RT-qPCR. (B) Transfection efficiency was measured by western blotting. (C) Viability of A549 cells was detected by MTT assay. (D) Viability of A549 cells was investigated by Cell Counting Kit- 8 . The experiments were repeated $\geq 3$ times. ${ }^{* *} \mathrm{P}<0.01$ and ${ }^{* * *} \mathrm{P}<0.001$ vs. the siNC group. BRF2, transcription factor II B-related factor 2 ; siNC, negative control for siRNA; siRNA, small interfering RNA for BRF2; RT-qPCR, reverse transcription-quantitative PCR.
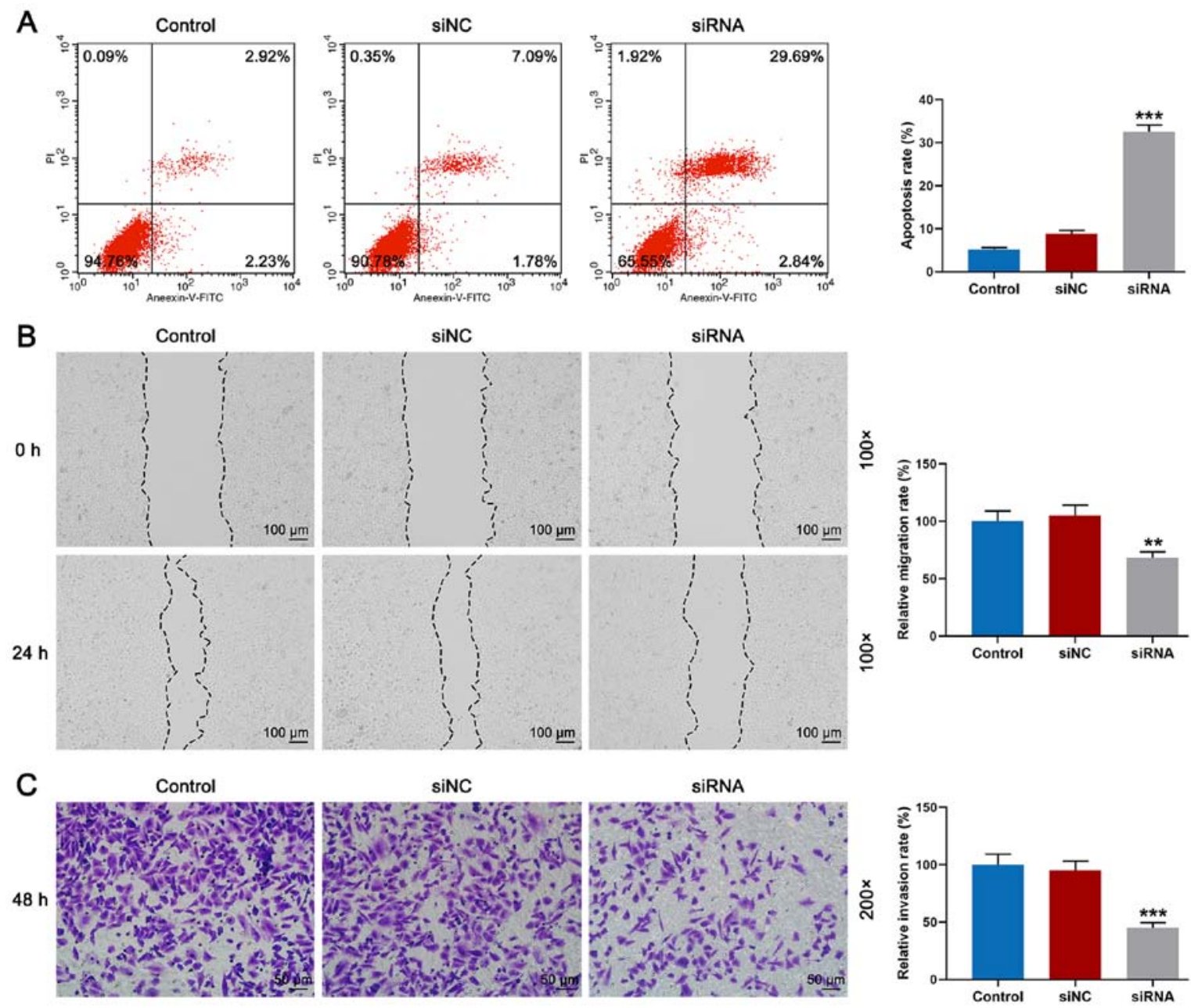

Figure 3. Effects of BRF2 siRNA on cell apoptosis, migration and invasion. (A) Apoptosis of A549 cells was measured by flow cytometry and BRF2 siRNA transfection promoted apoptosis. (B) Migration of A549 cells was measured by wound-healing assay. Magnification, x100; scale bar, $100 \mu \mathrm{m}$. (C) Cell invasion of A549 cells was measured by Transwell assay, and BRF2 siRNA inhibited cell invasion. The experiments were repeated $\geq 3$ times. Magnification, $x 200$; scale bar, $50 \mu \mathrm{m}$. ${ }^{* *} \mathrm{P}<0.01$ and ${ }^{* * * *} \mathrm{P}<0.001$ vs. siNC. BRF2, transcription factor II B-related factor 2; siNC, negative control for siRNA; siRNA, small interfering RNA for BRF2. 

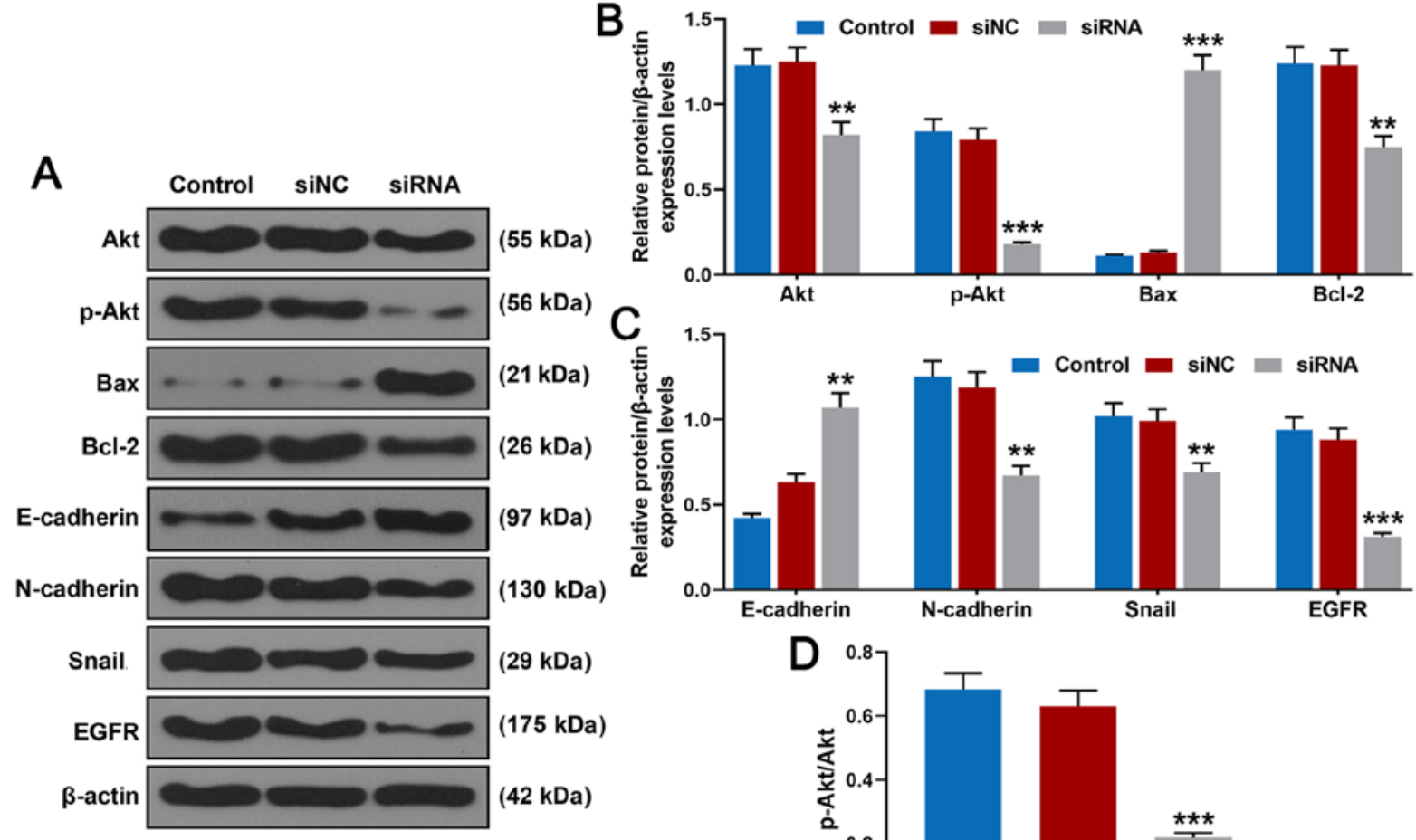

$\mathrm{N}$-cadherin, Snail and EGFR protein expression in A549 cells was detected by western blotting. (B) BRF2 siRNA inhibited p-Akt, Akt and Bcl-2 protein expression but increased Bax protein expression. (C) BRF2 siRNA reduced N-cadherin, Snail and EGFR protein expressions but promoted E-cadherin protein expression. (D) BRF2 siRNA suppressed phosphorylation of Akt. The experiments were repeated at least 3 times. ${ }^{* *} \mathrm{P}<0.01$ and ${ }^{* * *} \mathrm{P}<0.001 \mathrm{vs}$. siNC. BRF2, transcription factor II B-related factor 2; siNC, negative control for siRNA; siRNA, small interfering RNA for BRF2; p, phosphorylated.

$\mathrm{P}<0.001)$. Meanwhile, cell migration and invasion were detected by wound-healing and Transwell assays. As shown in Fig. 3B, it was observed that the relative migration rate of the siRNA group was significantly lower than that noted in the siNC group (Fig. 3B, $\mathrm{P}<0.01$ ). Furthermore, the result of Fig. 3C revealed that invasion of A549 cells transfected with BRF2 siRNA was significantly reduced (Fig. 3C, P<0.001).

Knockdown of BRF2 inhibits the protein expression levels of Akt, p-Akt, Bcl-2, N-cadherin, Snail and EGFR and increases those of Bax and E-cadherin. The western blot analysis (Fig. 4A and B) revealed that following transfection of BRF2 siRNA, relative protein expression levels of Akt ( $\mathrm{P}<0.01$ vs. siNC), p-Akt ( $\mathrm{P}<0.001$ vs. siNC) and Bcl-2 ( $\mathrm{P}<0.01$ vs. siNC) were suppressed, while relative protein expression level of Bax was significantly promoted. Furthermore, as demonstrated in Fig. 4C, relative protein expression levels of $\mathrm{N}$-cadherin $(\mathrm{P}<0.01$ vs. siNC), Snail ( $\mathrm{P}<0.01$ vs. siNC) and EGFR ( $\mathrm{P}<0.001$ vs. siNC) were significantly inhibited. Notably, protein expression of E-cadherin $(\mathrm{P}<0.01$ vs. siNC) was significantly promoted following transfection of BRF2 siRNA. In addition, the results further confirmed that BRF2 siRNA suppressed phosphorylation of Akt (Fig. 4D, $\mathrm{P}<0.001$ vs. siNC).

\section{Discussion}

Lung cancer accounts for a large proportion of cancer-related deaths (24). Although diagnostic and therapeutic techniques have been improved, treatment results are far from satisfactory $(25,26)$. Therefore, it is crucial to improve current understanding on tumor pathogenesis, gene expression profiles and tumor biology (27).

Melchor et al (28) observed increased transcription factor II B (TFIIB)-related factor 2 (BRF2) gene expression in breast cancer, and that BRF2 gene expression products are significantly higher in breast cancer tissues compared normal breast tissues. Furthermore, they identified a correlation between BRF2 overexpression and clinical outcomes (29). It has been shown that $\sim 40 \%$ of lung squamous cell carcinoma is closely related to the local amplification of chromosome $8 \mathrm{p} 12$ through comparative genomic hybridization (29). During the invasion stage of lung squamous cell carcinoma, the oncogene BRF is frequently activated (30). These findings indicate that BRF2 protein has an active expression in various tumors and is closely related to invasion and migration of various tumors. The present study found that BRF2 expression was increased in lung cancer cells compared with that in normal adjacent tissues.

miR-4299 is a key molecule of the cell survival pathway PI3K/Akt; the study of Yang et al (31) found that miR-4299 suppresses the progression of non-small lung cancer (NSCLC) by modulating the activation of the PTEN/AKT/PI3K signaling pathway; thus, it may serve as an independent candidate marker for prognosis of NSCLC patients. Croton tiglium extract can elevate expression of Bax genes and reduce expression of Bcl-2 genes to induce A549 cell apoptosis (32). In addition, 
the physiological function of EGFR is to regulate epithelial tissue development and homeostasis (33). In pathological settings, mostly in lung and breast cancers and glioblastoma, EGFR is a driver of tumorigenesis (33). In the present study, following cell transfection with BRF2 siRNA, the protein expression levels of Akt, p-Akt, Bcl-2 and EGFR in A549 cells were inhibited, while Bax protein expression was increased, suggesting that silencing of BRF2 inhibited the activation of cell survival pathway PI3K/Akt, and promoted the activation of cell apoptosis.

Farmakovskaya et al (34) demonstrated that suppression of E-cadherin expression increases cancer stem cells in human A549 lung adenocarcinoma and stimulates tumor growth. In addition, $\mathrm{N}$-cadherin induces cell survival, migration, and invasion by modulating intracellular signaling molecules. As shown by Quintanal-Villalonga et al (35), the FGFR4-388arg variant promotes lung cancer progression through $\mathrm{N}$-cadherin induction. Reducing miR-22 expression promotes epithelial-mesenchymal transition (EMT) and invasion of lung cancer cells by elevating Snail expression (36). According to the results of western blot analysis in the present study, transfection of BRF2 siRNA into A549 cells increased E-cadherin expression but reduced $\mathrm{N}$-cadherin expression.

Consistent with a previous study (37), in the present study silencing of BRF2 protein expression reduced the migration and invasion of NSCLC, suggesting that BRF2 expression plays an important role in invasiveness of NSCLC cells, possibly through EMT, which involves increased Snail expression and abnormal expression of E-cadherin and N-cadherin. Furthermore, Gouge et al (38) found that BRF2 redox-dependent regulation constitutes a cellular blockade, which is capable of generating pro-apoptotic signals upon prolonged oxidative stress in lung and breast cancers by limiting the availability of SeCys tRNA. Wang et al (2) suggested that miR-373 may function as a tumor suppressor in NSCLC by attenuating the expression of BRF2 to inhibit proliferation. These above findings are in line with the results of the current study, in which the knockdown of BRF2 inhibited A549 cell migration and invasion, suppressed A549 cell proliferation, and enhanced apoptosis of A549 cells. It should be noted that the present study did not assess the findings in vivo in animal experiments and that the results should be verified in more cell lines. In addition, the mechanism of BRF2 remains to be further elucidated.

The findings of the present study revealed that BRF2 protein plays an important role in lung cancer cells and supports the hypothesis that BRF2 protein could serve as a novel target for lung cancer therapy. However, the role of BRF2 in the occurrence and development of lung cancer should be further verified. Thus, in future research, the effect of BRF2 on tumors in vivo should be explored by establishing animal models of lung cancer.

\section{Acknowledgements}

Not applicable.

\section{Funding}

No funding was received.

\section{Availability of data and materials}

The analyzed data sets generated during the study are available from the corresponding author on reasonable request.

\section{Authors' contributions}

YB made substantial contributions to conception and design. QiuL, QiaL and RP were responsible for data acquisition, data analysis and interpretation. YB drafted the article and critically revising it for important intellectual content. All authors agreed to be accountable for all aspects of the work in ensuring that questions related to the accuracy or integrity of the work are appropriately investigated and resolved. All authors reviewed and approved the final manuscript.

\section{Ethics approval and consent to participate}

Not applicable.

\section{Patient consent for publication}

Not applicable.

\section{Competing interests}

The authors declare that they have no competing interests.

\section{References}

1. Liu H, Han L, Liu Z and Gao N: Long noncoding RNA MNX1-AS1 contributes to lung cancer progression through the miR-527/BRF2 pathway. J Cell Physiol 234: 13843-13850, 2019.

2. Wang L, Qu J, Zhou L, Liao F and Wang J: MicroRNA-373 Inhibits Cell Proliferation and Invasion via Targeting BRF2 in Human Non-small Cell Lung Cancer A549 Cell Line. Cancer Res Treat 50: 936-949, 2018.

3. Lu J and Han B: Liquid Biopsy Promotes Non-Small Cell Lung Cancer Precision Therapy. Technol Cancer Res Treat 17: 1533033818801809, 2018.

4. Collins LG, Haines C, Perkel R and Enck RE: Lung cancer: Diagnosis and management. Am Fam Physician 75: 56-63, 2007.

5. Tian Y, Wang C and Lu M: BRF2 as a promising indicator for radical lymph-node dissection surgery in patients with $\mathrm{cN} 0$ squamous cell carcinoma of the middle thoracic esophagus. Surg Today 49: 158-169, 2019.

6. Verma N, Hurlburt AM, Wolfe A, Kim MK, Kang YS, Kang JJ and Stumph WE: Bdp1 interacts with SNAPc bound to a U6, but not U1, snRNA gene promoter element to establish a stable protein-DNA complex. FEBS Lett 592: 2489-2498, 2018.

7. McQueen C, Hughes GL and Pownall ME: Skeletal muscle differentiation drives a dramatic downregulation of RNA polymerase III activity and differential expression of Polr3g isoforms. Dev Biol 454: 74-84, 2019.

8. Geiduschek EP and Kassavetis GA: The RNA polymerase III transcription apparatus. J Mol Biol 310: 1-26, 2001.

9. Saxena A, Ma B,SchrammL and Hernandez N: Structure-function analysis of the human TFIIB-related factor II protein reveals an essential role for the C-terminal domain in RNA polymerase III transcription. Mol Cell Biol 25: 9406-9418, 2005.

10. Song W, Filonov GS, Kim H, Hirsch M, Li X, Moon JD and Jaffrey SR: Imaging RNA polymerase III transcription using a photostable RNA-fluorophore complex. Nat Chem Biol 13: 1187-1194, 2017.

11. Scott PH, Cairns CA, Sutcliffe JE, Alzuherri HM, McLees A, Winter AG and White RJ: Regulation of RNA polymerase III transcription during cell cycle entry. J Biol Chem 276: 1005-1014, 2001.

12. Lei J, Chen S and Zhong S: Abnormal expression of TFIIIB subunits and RNA Pol III genes is associated with hepatocellular carcinoma. Liver Res 1: 112-120, 2017. 
13. White RJ: RNA polymerase III transcription - a battleground for tumour suppressors and oncogenes. Eur J Cancer 40: 21-27, 2004.

14. Cabarcas S, Jacob J, Veras I and Schramm L: Differential expression of the TFIIIB subunits Brf1 and Brf2 in cancer cells. BMC Mol Biol 9: 74, 2008.

15. Johnson SA, Dubeau L, Kawalek M, Dervan A, Schönthal AH, Dang CV and Johnson DL: Increased expression of TATA-binding protein, the central transcription factor, can contribute to oncogenesis. Mol Cell Biol 23: 3043-3051, 2003.

16. Srihari S, Kalimutho M, Lal S, Singla J, Patel D, Simpson PT, Khanna KK and Ragan MA: Understanding the functional impact of copy number alterations in breast cancer using a network modeling approach. Mol Biosyst 12: 963-972, 2016.

17. Ng CK, Martelotto LG, Gauthier A, Wen HC, Piscuoglio S, Lim RS, Cowell CF, Wilkerson PM, Wai P, Rodrigues DN, et al: Intra-tumor genetic heterogeneity and alternative driver genetic alterations in breast cancers with heterogeneous HER2 gene amplification. Genome Biol 16: 107, 2015.

18. Lockwood WW, Chari R, Coe BP, Thu KL, Garnis C, Malloff CA, Campbell J, Williams AC, Hwang D, Zhu CQ, et al: Integrative genomic analyses identify BRF2 as a novel lineage-specific oncogene in lung squamous cell carcinoma. PLoS Med 7: e1000315, 2010

19. Almanza A, Carlesso A, Chintha C, Creedican S, Doultsinos D, Leuzzi B, Luís A, McCarthy N, Montibeller L, More S, et al Endoplasmic reticulum stress signalling - from basic mechanisms to clinical applications. FEBS J 286: 241-278, 2019.

20. Garcia MJ, Pole JC, Chin SF, Teschendorff A, Naderi A, Ozdag H, Vias M, Kranjac T, Subkhankulova T, Paish C, et al: A $1 \mathrm{Mb}$ minimal amplicon at 8p11-12 in breast cancer identifies new candidate oncogenes. Oncogene 24: 5235-5245, 2005.

21. Livak KJ and Schmittgen TD: Analysis of relative gene expression data using real-time quantitative PCR and the 2(-Delta Delta C(T)) Method. Methods 25: 402-408, 2001.

22. Guo Q, Li H, Liu J, Xu L, Yang L, Sun Z and Zhou B: Tunicamycin aggravates endoplasmic reticulum stress and airway inflammation via PERK-ATF4-CHOP signaling in a murine model of neutrophilic asthma. J Asthma 54: 125-133, 2017.

23. Jin J, Zhao L, Zou W, Shen W, Zhang H and He Q: Activation of Cyclooxygenase-2 by ATF4 During Endoplasmic Reticulum Stress Regulates Kidney Podocyte Autophagy Induced by Lupus Nephritis. Cell Physiol Biochem 48: 753-764, 2018.

24. Thawani R, McLane M, Beig N, Ghose S, Prasanna P, Velcheti V and Madabhushi A: Radiomics and radiogenomics in lung cancer: A review for the clinician. Lung Cancer 115: 34-41, 2018

25. Hirsch FR, Scagliotti GV, Mulshine JL, Kwon R, Curran WJ Jr, Wu YL and Paz-Ares L: Lung cancer: Current therapies and new targeted treatments. Lancet 389:299-311, 2017.

26. Herbst RS, Heymach JV and Lippman SM: Lung cancer. N Engl J Med 359: 1367-1380, 2008
27. Hashemi ZS, Khalili S, Forouzandeh Moghadam M and Sadroddiny E: Lung cancer and miRNAs: A possible remedy for anti-metastatic, therapeutic and diagnostic applications. Expert Rev Respir Med 11: 147-157, 2017

28. Melchor L, Garcia MJ, Honrado E, Pole JC, Alvarez S, Edwards PA, Caldas C, Brenton JD and Benítez J: Genomic analysis of the 8p11-12 amplicon in familial breast cancer. Int J Cancer 120: 714-717, 2007.

29. Cabarcas S and Schramm L: RNA polymerase III transcription in cancer: The BRF2 connection. Mol Cancer 10: 47, 2011.

30. Rosenwald IB: The role of translation in neoplastic transformation from a pathologist's point of view. Oncogene 23: 3230-3247, 2004.

31. Yang WB,Zhang WP, Shi JL and Wang JW: miR-4299 suppresses non-small cell lung cancer cell proliferation, migration and invasion through modulating PTEN/AKT/PI3K pathway. Eur Rev Med Pharmacol Sci 22: 3408-3414, 2018.

32. Khodapasand E, Jafarzadeh N, Farrokhi F, Kamalidehghan B and Houshmand $\mathrm{M}$ : Is $\mathrm{Bax} / \mathrm{Bcl}-2$ ratio considered as a prognostic marker with age and tumor location in colorectal cancer? Iran Biomed J 19: 69-75, 2015.

33. Sigismund S, Avanzato D and Lanzetti L: Emerging functions of the EGFR in cancer. Mol Oncol 12: 3-20, 2018.

34. Farmakovskaya M, Khromova N, Rybko V, Dugina V, Kopnin B and Kopnin P: E-Cadherin repression increases amount of cancer stem cells in human A549 lung adenocarcinoma and stimulates tumor growth. Cell Cycle 15: 1084-1092, 2016.

35. Quintanal-Villalonga Á, Ojeda-Márquez L, Marrugal Á, Yagüe P, Ponce-Aix S, Salinas A, Carnero A, Ferrer I, Molina-Pinelo S and Paz-Ares L: The FGFR4-388arg Variant Promotes Lung Cancer Progression by N-Cadherin Induction. Sci Rep 8: 2394, 2018.

36. Zhang K, Li XY, Wang ZM, Han ZF and Zhao YH: miR-22 inhibits lung cancer cell EMT and invasion through targeting Snail. Eur Rev Med Pharmacol Sci 21: 3598-3604, 2017.

37. Tian Y, Lu M, Yue W, Li L, Li S, Gao C, Si L, Qi L, Hu W and Tian H: TFIIB-related factor 2 is associated with poor prognosis of nonsmall cell lung cancer patients through promoting tumor epithelial-mesenchymal transition. BioMed Res Int 2014: 530786 , 2014.

38. Gouge J, Satia K, Guthertz N, Widya M, Thompson AJ, Cousin P, Dergai O, Hernandez N and Vannini A: Redox Signaling by the RNA Polymerase III TFIIB-Related Factor Brf2. Cell 163: 1375-1387, 2015

This work is licensed under a Creative Commons Attribution-NonCommercial-NoDerivatives 4.0 International (CC BY-NC-ND 4.0) License. 